\title{
COMMENTARY
}

\section{PSP/reg: a new stone in sepsis biomarkers?}

\author{
Stefano Busani and Massimo Girardis* \\ See related research by Que et al., http://ccforum.com/content/16/4/R114
}

\section{Abstract}

Rapid diagnosis, appropriate management, and time are the key factors for improving survival rate in many emergency clinical scenarios such as acute myocardial infarction, pulmonary embolism, cerebral stroke, and severe sepsis. Clinical signs and electrocardiographic, radiological, and echographic investigations associated with biomarkers usually allow a quick diagnosis in all of the above situations, except severe sepsis, in which the diagnosis in the early phases is often only presumptive. In sepsis, microbiological cultures are still considered the 'gold standard'for diagnosis, whereas the numerous biomarkers investigated are actually valuable only for patient stratification and evaluation of clinical course. In this issue of Critical Care, Que and colleagues describe the prognostic value of pancreatic stone protein/regenerating protein (PSP/reg) concentration in patients with severe infections. The data reported are interesting, but several questions about this biomarker arise, and further studies are needed to understand its role in sepsis and clinical practice.
\end{abstract}

In recent years, several biomarkers, such as procalcitonin (PCT), interleukin-6 (IL-6), soluble triggering receptor expressed on myeloid cells-1, and soluble urokinase-type plasminogen activator receptor, have been investigated to discriminate non-infectious diseases from sepsis. In this issue of Critical Care, Que and colleagues [1] describe the prognostic value of pancreatic stone protein/regenerating protein (PSP/reg) concentration in patients with severe infections.

PSP/reg functions historically have been reported mainly in regard to the pancreas, and, indeed, pancreatic acinar cells are considered the main source of this protein. PSP/reg was initially described as inhibiting pancreatic stone formation, but later this role was revised

*Correspondence: girardis.massimo@unimo.it

Intensive Care Department, University Hospital of Modena, L.go del Pozzo 71, 41100 Modena, Italy
[2]. Its serum elevation seemed to be correlated strongly with severe acute pancreatitis and less tightly with chronic pancreatitis and pancreatic cancer [3]. In the '90s, preclinical studies demonstrated that $\mathrm{PSP} / \mathrm{reg}$ appeared to stimulate islet B-cell growth and regeneration [4] and recently this function was hypothesized to play a role in a therapeutic approach to diabetes mellitus [5]. In recent years, PSP/reg investigations bypassed pancreatic diseases and focused on infection and inflammation [6]. Recent data from Keel and colleagues [7] showed that 83 patients with severe trauma but not pancreatic trauma had PSP/reg upregulation and that the number of patients with post-traumatic septic complications increased significantly. The authors postulated that PSP/ reg binds and activates neutrophils behaving as an acutephase protein that responds to injury during the early phase of infection. Boeck and colleagues [8] demonstrated predictive properties of $\mathrm{PSP} / \mathrm{reg}$ regarding survival in patients with ventilator-associated pneumonia with two cutoff values for predicting survival and death with high specificity.

The study by Que and colleagues [1] enrolled 107 patients admitted to the intensive care unit (ICU) with severe infections. Within 24 hours after ICU admission, the authors measured the concentrations of PSP/reg, Creactive protein, $\mathrm{PCT}$, inflammatory cytokines, leukocyte count, and severity scores - Acute Physiology and Chronic Health Evaluation II (APACHE II), Simplified Acute Physiology Score (SAPS) II and III, and Sequential Organ Failure Assessment (SOFA) - and correlated all of these parameters with in-hospital mortality. The authors demonstrated that PSP/reg and SAPS III were the only two variables associated with mortality and thus concluded that PSP/reg is the only bedside biomarker useful in predicting the outcome of patients with sepsis. The data presented in the article are sound, but several questions arise: Is PSP/reg related to infection or to tissue hypoperfusion? Do comorbidities affect PSP/reg values in patients with sepsis? Is a single PSP/reg measurement helpful in clinical practice?

Tumor necrosis factor-alpha, interferon-gamma, and IL-6 are known to induce PSP/reg expression and thus $\mathrm{PSP} /$ reg can be assumed as a potential sepsis marker [9]. Nevertheless, to our knowledge, no studies on PSP/reg 
concentrations in other types of shock (that is, hemorrhagic or cardiogenic) have been performed. So the high values observed in patients with septic shock may not necessarily be related to the infection pathway but may be due to tissue hypoperfusion or systemic inflammatory response or both. PSP/reg is increased in patients with chronic renal failure, gastric cancer, peptic ulcer, liver cirrhosis, or diabetes mellitus [2]. Que and colleagues [1] reported that 'most patients had at least one comorbid condition', but unfortunately the authors did not analyze how these comorbidities affected the initial levels of PSP/ reg. A useful biomarker ought to fulfill different clinical needs such as early diagnosis and accurate evaluation of clinical course. A single PSP/reg measurement correlated with the severity of the disease, but we do not know whether this biomarker is reliable in the early diagnosis of bacterial infection or, for instance, in monitoring the therapy response. Que and colleagues added new and interesting findings on the relationships between PSP/reg and patients with severe sepsis. However, there is a long way to go before $\mathrm{PSP} / \mathrm{reg}$, along with other biomarkers, can be implemented in clinical practice.

\section{Abbreviations}

ICU, intensive care unit; IL-6, interleukin-6; PCT, procalcitonin; PSP/reg, pancreatic stone protein/regenerating protein; SAPS, Simplified Acute Physiology Score.

\section{Competing interests}

The authors declare that they have no competing interests.

\section{References}

1. Que YA, Delodder F, Guessous I, Graf R, Bain M, Calandra T, Liaudet L, Eggimann P: Pancreatic stone protein as an early biomarker predicting mortality in a prospective cohort of patients with sepsis requiring ICU management. Crit Care 2012, 16:R114.

2. Jin CX, Hayakawa T, Ko SB, Ishiguro H, Kitagawa M: Pancreatic stone protein/ regenerating protein family in pancreatic and gastrointestinal diseases. Intern Med 2011, 50:1507.

3. Hayakawa T, Kondo T, Shibata T, Kitagawa M, Sakai Y, Sobajima H, Tanikawa M, Nakae Y, Hayakawa S, Katsuzaki T, Tatemichi N: Serum pancreatic stone protein in pancreatic diseases. Int J Pancreatol 1993, 13:97.

4. Watanabe T, Yonemura Y, Yonekura H, Suzuki Y, Miyashita H, Sugiyama K, Moriizumi S, Unno M, Tanaka O, Kondo H, Bone AJ, Takasawa S, Okamoto H: Pancreatic beta-cell replication and amelioration of surgical diabetes by Reg protein. Proc Natl Acad SciU S A 1994, 91:3589.

5. Hou WR, Xie SN, Wang HJ, Su YY, Lu JL, Li LL, Zhang SS, Xiang M: Intramuscular delivery of a naked DNA plasmid encoding proinsulin and pancreatic regenerating III protein ameliorates type 1 diabetes mellitus. Pharmacol Res 2011, 63:320.

6. Cash HL, Whitham CV, Behrendt CL, Hooper LV: Symbiotic bacteria direct expression of an intestinal bactericidal lectin. Science 2006, 313:1126.

7. Keel M, Härter L, Reding T, Sun LK, Hersberger M, Seifert B, Bimmler D, Graf R: Pancreatic stone protein is highly increased during posttraumatic sepsis and activates neutrophil granulocytes. Crit Care Med 2009, 37:1642.

8. Boeck L, Graf R, Eggimann P, Pargger H, Raptis DA, Smyrnios N, Thakkar N, Siegemund M, Rakic J, Tamm M, Stolz D: Pancreatic stone protein: a marker of organ failure and outcome in ventilator-associated pneumonia. Chest 2011, 140:925.

9. Dusetti NJ, Mallo GV, Ortiz EM, Keim V, Dagorn JC, lovanna JL: Induction of lithostathine/reg mRNA expression by serum from rats with acute pancreatitis and cytokines in pancreatic acinar AR-42J cells. Arch Biochem Biophys 1996, 330:129.

doi:10.1186/cc11433

Cite this article as: Busani S, Girardis M: PSP/reg: a new stone in sepsis biomarkers? Critical Care 2012, 16:1??. 